\title{
Peritoneal dialysis treatment for severe lupus nephritis patients complicated with essential organ dysfunction
}

\author{
YAN ZHOU, YUSHENG YU, ZHENG TANG, SHIJUN LI, WEIXIN HU, CHUNLEI LUO and ZHIHONG LIU \\ Research Institute of Nephrology, Jinling Hospital, School of Medicine, \\ Nanjing University, Nanjing, Jiangsu 210002, P.R. China
}

Received December 7, 2013; Accepted April 29, 2014

DOI: $10.3892 /$ etm.2015.2799

\begin{abstract}
The aim of the present study was to evaluate the clinical efficacy of peritoneal dialysis (PD) in patients with severe lupus nephritis (LN) complicated with organ dysfunction. In total, 13 severe LN patients complicated with multiple-organ dysfunction, who underwent PD treatment between November 2003 and September 2010, were enrolled in the study. Six patients received methylprednisolone pulse therapy due to lupus activity and progressive renal failure. These patients were complicated with severe edema, cardiac insufficiency and severe hypoalbuminemia. PD was applied to the patients, followed by the administration of immunosuppressants. Patients were followed-up to review the parameters of renal function, the immunological indexes and the systemic lupus erythematosus disease activity index. The results indicated that the general state of health was markedly improved following PD treatment, with edema abatement and improvement of heart function and physical strength. Serum creatinine levels significantly decreased from $6.3 \pm 1.6$ to $2.6 \pm 1.0 \mathrm{mg} / \mathrm{dl}$. A total of 10 cases ceased PD treatment during the follow-up, while three cases continued PD to the end of the follow-up period. The levels of albumin and hemoglobin exhibited a marked increase from $29.7 \pm 5.7$ to $35.2 \pm 5.5 \mathrm{~g} / 1$ and $8.7 \pm 1.8$ to $9.8 \pm 1.8 \mathrm{~g} / \mathrm{l}$, respectively. There was one case of peritonitis, one case of peritoneal leakage and two cases of pneumonia. Therefore, PD may be a successful treatment method for severe LN patients complicated with essential organ dysfunction. PD not only improved the symptoms of edema and heart failure, but also played an important role in preserving residual renal function and improving the nutritional state of the patients. Thus, PD can be considered as a treatment option for patients with severe LN associated with acute kidney injury, however, selecting a suitable immunosuppressant during PD treatment is essential.
\end{abstract}

Correspondence to: Professor Zheng Tang, Research Institute of Nephrology, Jinling Hospital, School of Medicine, Nanjing University, 305 Zhongshan East Road, Nanjing, Jiangsu 210002, P.R. China

E-mail: tangzhengdoctor1@yeah.net

Key words: peritoneal dialysis, systemic lupus erythematosus, residual renal function, immunosuppressant

\section{Introduction}

Systemic lupus erythematosus (SLE) is an autoimmune inflammatory disease which involves multiple organs. The disease is progressively aggravated without intervention. Therapy with immunosuppressants controls the progression of the disease in the early stages (1-3). However, successful treatment of severe lupus nephritis (LN), particularly when complicated with acute kidney injury (AKI), cardiovascular or neuropsychiatric involvement, remains a problem. Peritoneal dialysis (PD) has the advantages of hemodynamic stability, residual renal function (RRF) preservation, home dialysis and lower costs. Both of PD and hemodialysis dialysis are used to treat kidney failure. PD uses the lining of the abdominal cavity (peritoneal membrane) and a solution (dialyusate) to remove waste and extra fluid from the body. Hemodialysis uses a man-made membrane (dialyzer) to filter waste and remove extra fluid from the blood. Previously, studies have investigated the effects of PD in the treatment of AKI (4-7). However, few observations with regard to $\mathrm{PD}$ as a treatment method for severe LN patients with multiple-organ dysfunction have been reported. Therefore, the aim of the present study was to investigate the effect of PD as therapy for patients with severe LN.

\section{Patients and methods}

Patients. In total, 13 patients, including 10 females and 3 males with a mean age of $36.3 \pm 13.3$ years (age range, $18-54$ years) that had been admitted to the Department of Nephrology at Jinling Hospital (Nanjing, China) between November 2003 and September 2010, were included in the study. All the patients were diagnosed with severe LN with rapid progressive glomerulonephritis (RPGN). Among the patients, four individuals had heart diseases, including enlargement of the cardiothoracic ratio, slight or moderate pericardial effusion and pulmonary artery hypertension, and one patient had lupus encephalopathy. The present study was approved by the ethics committee of Nanjing University (Nanjing, China). All of the patients approved the present study and gave their informed consents.

Renal biopsy. A renal biopsy was performed in all the patients. According to the 2003 International Society of 
Table I. Baseline clinical and renal pathological characteristics.

\begin{tabular}{|c|c|c|c|c|c|c|}
\hline Case & Gender & Age (years) & BUN (mg/dl) & $\operatorname{Scr}(\mathrm{mg} / \mathrm{dl})$ & Pathology & Crescents (\%) \\
\hline 1 & $\mathrm{~F}$ & 41 & 50 & 6.6 & Class IV, TMA & 0 \\
\hline 2 & $\mathrm{~F}$ & 51 & 94 & 4.2 & Class IV + V & 10 , fibrocellular \\
\hline 3 & M & 24 & 137 & 9.5 & Class IV + V & 83 , fibrocellular \\
\hline 4 & $\mathrm{~F}$ & 24 & 79 & 7.5 & $\begin{array}{c}\text { Class IV, } 53 \% \\
\text { glomerular sclerosis }\end{array}$ & 40 , fibrocellular \\
\hline 5 & $\mathrm{~F}$ & 54 & 103 & 6.1 & Class IV, TMA & 0 \\
\hline 6 & $\mathrm{~F}$ & 21 & 106 & 5.5 & Class IV + V & 27 , fibrocellular \\
\hline 7 & M & 44 & 93 & 6.7 & $\begin{array}{c}\text { Class IV, } 59 \% \\
\text { glomerular sclerosis }\end{array}$ & 28 , cellular \\
\hline 8 & M & 18 & 77 & 4.4 & Class V + IV & 77 , cellular \\
\hline 9 & $\mathrm{~F}$ & 43 & 120 & 8.2 & Class IV & 84 , cellular \\
\hline 10 & $\mathrm{~F}$ & 41 & 112 & 5.4 & Class IV & 0 \\
\hline 11 & $\mathrm{~F}$ & 41 & 69 & 4.3 & Class IV & 16 , cellular \\
\hline 12 & $\mathrm{~F}$ & 35 & 44 & 9.3 & Class IV + V, TMA & $\begin{array}{l}\text { 6.5, fibrocellular; } \\
\text { Class IV 16, fibro }\end{array}$ \\
\hline 13 & $\mathrm{~F}$ & 46 & 46 & 8.5 & Class III & 26.7 fibrocellular \\
\hline
\end{tabular}

F, female; M, male; Scr, serum creatinine; BUN, blood urea nitrogen; TMA, thrombotic microangiopathy.

Nephrology/Renal Pathology Society classification criteria $(2,6)$, seven patients were class IV, five patients were class IV + V and one patient was class III. Two patients had thrombotic microangiopathy. The crescent formations from 10 to $83 \%$ of glomeruli were observed in 9 patients.

Surgery and dialysis prescription. Open surgery was performed for PD catheter insertion. Patients were initially advised to have three to four daytime exchanges of one liter dextrose solution (1.5\%). After one week, the patients were discharged and the PD prescription was changed to two liters dextrose solution [ 1.5 or $2.5 \%$ according to the urine (UV) and ultrafiltration volume] with three or four daytime exchanges.

Data collection. All the patients underwent a peritoneal equilibration test at the outpatient department in the first month following discharge. Dialysate, urinary protein, urinary sediment, blood biochemistry, blood routine, autoantibody titer and complement levels were examined every two months. PD efficiency $(\mathrm{Kt} / \mathrm{V}, \mathrm{Ccl})$ was also evaluated. The levels of albumin, hemoglobin, serum creatinine were detected using a Blood biochemistry detection kit (Tiangen, Beijing, China). Other observational indexes included RRF, nutrition, systemic lupus erythematosus disease activity index (SLE-DAI) and immunosuppressant and infectious complications.

Statistical analysis. Measurement data are expressed as the mean \pm standard deviation. The Student's t-test was used to analyze the differences between the parameters prior to and following treatment. $\mathrm{P}<0.05$ was considered to indicate a statistically significant difference. Analyses were performed using SPSS software (SPSS, Inc., Chicago, IL, USA).

\section{Results}

Clinical and pathological features at the baseline. Clinical and pathological observations at the baseline are shown in Table I. All the patients had severe renal dysfunction and the levels of serum creatinine (Scr) ranged between 4.24 and $9.48 \mathrm{mg} / \mathrm{dl}$. Oliguria and anuria were present in five and two patients, respectively. Anemia was identified in 10 patients, with hemoglobin $(\mathrm{Hb})$ levels ranging between 4.9 and $10.4 \mathrm{~g} / \mathrm{dl}$. All the patients exhibited hypoalbuminemia with an average albumin (Alb) level of 29.7 $\pm 5.7 \mathrm{~g} / \mathrm{l}$, and eight patients had severe hypoalbuminemia with a level of $<30 \mathrm{~g} / \mathrm{l}$. In total, four cases were complicated with cardiac insufficiency, including chest distress, enlargement of the heart shadow and congestion of the lungs, as observed by X-ray.

Oral prednisone at a dose of 20-30 mg/day was administered to all the patients. Six patients received intravenous methylprednisolone pulse therapy $(0.5 \mathrm{~g} /$ day for three days per patient) prior to $\mathrm{PD}$.

Treatment and follow-up. The dialysis dose was six liters per day in 10 cases and 4 liters per day in the other three cases. Two cases were administered continuous ambulatory peritoneal dialysis (CAPD), while 11 cases received daytime ambulatory peritoneal dialysis (Table II). During the follow-up examinations, $\mathrm{Kt} / \mathrm{V}$ calculations were performed in all the patients and the results were all $>1.7$.

Short-term effects. Following PD, there were no patients with edema and the blood pressure was stable. No case developed heart failure and the indicators of renal function and serum Alb levels were all improved (Table II).

In total, 10 patients received oral mycophenolate (MMF) one month following PD. The dosage of MMF was initiated 
Table II. Clinical and dialysis indexes of the 13 patients prior to discharge.

\begin{tabular}{|c|c|c|c|c|c|c|c|c|c|c|}
\hline \multirow[b]{2}{*}{ Case } & \multirow{2}{*}{$\begin{array}{l}\text { Dialysis } \\
\text { prescription } \\
(\mathrm{ml} / \text { day })\end{array}$} & \multirow{2}{*}{$\begin{array}{l}\text { Time } \\
\text { (days) }\end{array}$} & \multirow[b]{2}{*}{ Edema } & \multirow{2}{*}{$\begin{array}{c}\text { UFV } \\
\text { (ml/day) }\end{array}$} & \multicolumn{2}{|c|}{ Alb (g/l) } & \multicolumn{2}{|c|}{$\operatorname{Scr}(\mathrm{mg} / \mathrm{dl})$} & \multicolumn{2}{|c|}{ UV (ml/day) } \\
\hline & & & & & Pre PD & Discharge & Pre PD & Discharge & Pre PD & Discharge \\
\hline 1 & CAPD, 6000 & 14 & No & 1000 & 38.3 & 39.3 & 6.58 & 5.68 & 0 & 100 \\
\hline 2 & DAPD, 6000 & 27 & No & 200 & 27.2 & 21.6 & 4.24 & 8.04 & 0 & 400 \\
\hline 3 & DAPD, 4000 & 11 & No & 100 & 26.6 & 26.6 & 9.48 & 3.80 & 1400 & 400 \\
\hline 4 & DAPD, 6000 & 8 & No & 100 & 21.0 & 21.2 & 7.49 & 7.30 & 300 & 800 \\
\hline 5 & DAPD, 6000 & 7 & No & 0 & 27.9 & 30.3 & 6.14 & 6.83 & 200 & 200 \\
\hline 6 & DAPD, 6000 & 12 & No & 700 & 31.1 & 31.6 & 5.52 & 4.22 & 700 & 1000 \\
\hline 7 & DAPD, 6000 & 9 & No & 0 & 29.1 & 29.1 & 6.69 & 6.29 & 800 & 800 \\
\hline 8 & DAPD, 6000 & 11 & No & 600 & 28.3 & 27.6 & 5.37 & 5.39 & 150 & 200 \\
\hline 9 & CAPD, 6000 & 23 & No & 1500 & 23.8 & 27.4 & 8.23 & 4.26 & 370 & 500 \\
\hline 10 & DAPD, 4000 & 9 & No & 100 & 33.0 & 34.3 & 5.42 & 3.89 & 810 & 900 \\
\hline 11 & DAPD, 4000 & 16 & No & 100 & 40.4 & 38.6 & 4.26 & 3.73 & 265 & 1100 \\
\hline 12 & DAPD, 6000 & 8 & No & 0 & 29.5 & 31.1 & 9.33 & 7.72 & 300 & 1500 \\
\hline 13 & DAPD, 6000 & 7 & No & 100 & 30.4 & 39.3 & 8.46 & 6.58 & 600 & 100 \\
\hline
\end{tabular}

All of the patients suffered from edema, however, edema disappeared when the patients left the hospital. In this Table, the out-hospital results are shown. UFV, ultrafiltration volume; Alb, albumin; UV, urine volume; Scr, serum creatinine; CAPD, continuous ambulatory peritoneal dialysis; DAPD, daytime ambulatory peritoneal dialysis; PD, peritoneal dialysis.

Table III. Clinical and dialysis indexes of the 13 patients during the follow-up.

\begin{tabular}{|c|c|c|c|c|c|c|c|c|c|c|c|c|c|}
\hline \multirow[b]{2}{*}{ Case } & \multirow{2}{*}{$\begin{array}{c}\text { Dialysis } \\
\text { prescription } \\
(\mathrm{ml} / \text { day })\end{array}$} & \multirow[b]{2}{*}{$\begin{array}{c}\text { Follow-up } \\
\text { (months) }\end{array}$} & \multirow[b]{2}{*}{ Outcome } & \multicolumn{2}{|c|}{$\mathrm{rGFR}(\mathrm{ml} / \mathrm{min})$} & \multicolumn{2}{|c|}{$\mathrm{Alb}(\mathrm{g} / \mathrm{l})$} & \multicolumn{2}{|c|}{ Scr (mg/dl) } & \multicolumn{2}{|c|}{$\mathrm{Hb}(\mathrm{g} / \mathrm{dl})$} & \multicolumn{2}{|c|}{ UV (ml/day) } \\
\hline & & & & $\begin{array}{l}\text { Pre } \\
\text { PD }\end{array}$ & $\begin{array}{l}\text { Post } \\
\text { PD }\end{array}$ & $\begin{array}{l}\text { Pre } \\
\text { PD }\end{array}$ & $\begin{array}{l}\text { Post } \\
\text { PD }\end{array}$ & $\begin{array}{l}\text { Pre } \\
\text { PD }\end{array}$ & $\begin{array}{l}\text { Post } \\
\text { PD }\end{array}$ & $\begin{array}{l}\text { Pre } \\
\text { PD }\end{array}$ & $\begin{array}{l}\text { Post } \\
\text { PD }\end{array}$ & $\begin{array}{l}\text { Pre } \\
\text { PD }\end{array}$ & $\begin{array}{l}\text { Post } \\
\text { PD }\end{array}$ \\
\hline 1 & CAPD, 6000 & 26 & Discontinued & 0.0 & 11.6 & 38.3 & 43.8 & 6.58 & 2.70 & 4.9 & 12.3 & 0 & 2000 \\
\hline 2 & DAPD, 6000 & 4 & Discontinued & 0.0 & 21.6 & 27.2 & 25.1 & 4.24 & 1.29 & 7.9 & 7.8 & 0 & 1500 \\
\hline 3 & DAPD, 4000 & 6 & Continued & 7.3 & 18.1 & 26.6 & 38.7 & 9.48 & 3.18 & 9.0 & 10.7 & 1400 & 1300 \\
\hline 4 & DAPD, 6000 & 4 & Discontinued & 7.1 & 19.9 & 21.0 & 34.6 & 7.49 & 3.05 & 9.3 & 6.7 & 300 & 600 \\
\hline 5 & DAPD, 6000 & 4 & Discontinued & 9.2 & 19.1 & 27.9 & 35.7 & 6.14 & 1.61 & 6.9 & 9.2 & 200 & 1500 \\
\hline 6 & DAPD, 6000 & 16 & Continued & 4.0 & 10.1 & 31.1 & 38.2 & 5.52 & 3.60 & 8.9 & 10.3 & 700 & 1400 \\
\hline 7 & DAPD, 6000 & 5 & Discontinued & 5.5 & 7.9 & 29.1 & 29.1 & 6.69 & 4.33 & 8.4 & 8.7 & 800 & 1000 \\
\hline 8 & DAPD, 6000 & 9 & Continued & 1.5 & 9.4 & 28.3 & 35.5 & 5.37 & 2.70 & 10.4 & 8.8 & 150 & 670 \\
\hline 9 & CAPD, 6000 & 9 & Discontinued & 1.8 & 16.3 & 23.8 & 29.4 & 8.23 & 2.56 & 8.3 & 10.3 & 370 & 1500 \\
\hline 10 & DAPD, 4000 & 5 & Discontinued & 9.2 & 23.0 & 33.0 & 38.6 & 5.42 & 1.42 & 11.5 & 12.7 & 810 & 2100 \\
\hline 11 & DAPD, 4000 & 5 & Discontinued & 5.8 & 13.2 & 40.4 & 38.4 & 4.26 & 1.62 & 10.3 & 10.4 & 265 & 1100 \\
\hline 12 & DAPD, 6000 & 7 & Discontinued & 3.6 & 27.9 & 29.5 & 38.7 & 9.33 & 1.55 & 5.4 & 9.5 & 300 & 1800 \\
\hline 13 & DAPD, 6000 & 5 & Discontinued & 5.4 & 28.0 & 30.4 & 34.3 & 8.46 & 1.76 & 4.8 & 11.6 & 600 & 1600 \\
\hline
\end{tabular}

Post PD refers to the last follow-up examination. CAPD, continuous ambulatory peritoneal dialysis; DAPD, daytime ambulatory peritoneal dialysis; rGFR, residual glomerular filtration rate; PD, peritoneal dialysis; Alb, albumin; Scr, serum creatinine; Hb, hemoglobin; UV, urine volume.

at $0.75-1.5 \mathrm{~g}$ twice daily and the concentration was measured after one or two months with three plasma samples, according to the strategy developed by Shaw et al (8); the dosage was titrated to maintain an area under the time concentration curve between 0 and $12 \mathrm{~h}$ of MMF at $20-45 \mathrm{mg} / \mathrm{h} / \mathrm{l}$. The additional three patients were treated with prednisone alone and the daily dosage of prednisone started at $\sim 0.6 \mathrm{mg} / \mathrm{kg} / \mathrm{day}$.
Long-term effects. The mean follow-up time was 8.1 \pm 6.3 months (range, 4-26 months). At the last follow-up examination, the UV had significantly increased between $454.1 \pm 428.6$ and $1333.6 \pm 475.8 \mathrm{ml}(\mathrm{P}<0.0001$; Table III; Fig. 1) and the Scr levels had significantly decreased between $6.3 \pm 1.6$ and $2.6 \pm 1.0 \mathrm{mg} / \mathrm{dl}(\mathrm{P}<0.0001$; Table III; Fig. 2). The residual glomerular filtration rate also significantly 


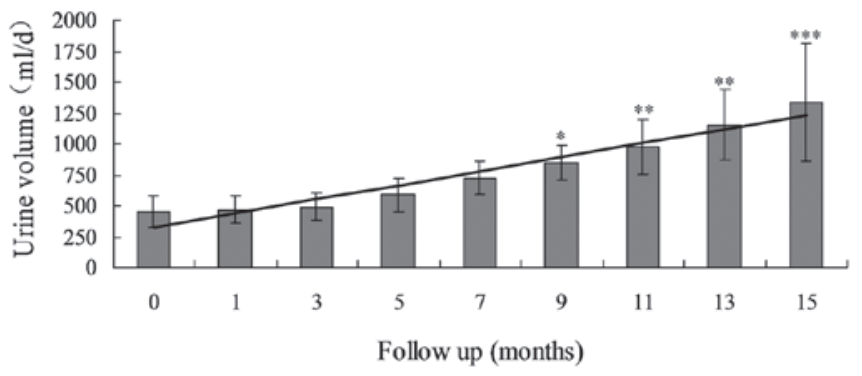

Figure 1. Changes in the UV in patients undergoing PD. ${ }^{*} \mathrm{P}<0.05,{ }^{* *} \mathrm{P}<0.01$ and ${ }^{* * *} \mathrm{P}<0.001$, vs. 0 month. $\mathrm{PD}$, peritoneal dialysis; $\mathrm{UV}$, urine volume.

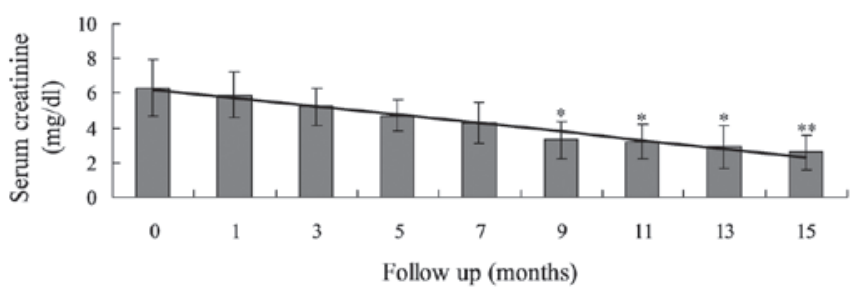

Figure 2. Changes in the Scr levels in patients undergoing PD. ${ }^{*} \mathrm{P}<0.05$ and ${ }^{* *} \mathrm{P}<0.01$, vs. 0 month. $\mathrm{PD}$, peritoneal dialysis; $\mathrm{Scr}$, serum creatinine.

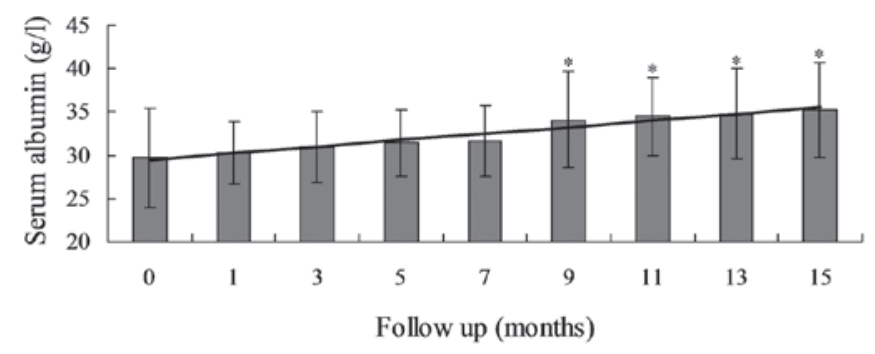

Figure 3. Changes in the serum Alb levels in patients undergoing PD. ${ }^{*} \mathrm{P}<0.05$, vs 0 month. PD, peritoneal dialysis; Alb, albumin.

increased from $4.6 \pm 3.2$ to $17.4 \pm 6.7 \mathrm{ml} / \mathrm{min}(\mathrm{P}<0.01)$. In addition, serum Alb and $\mathrm{Hb}$ levels markedly increased between 29.7 \pm 5.7 and $35.2 \pm 5.5 \mathrm{~g} / 1(\mathrm{P}=0.031)$ and between $8.7 \pm 1.8$ and $9.8 \pm 1.8 \mathrm{~g} / \mathrm{dl}(\mathrm{P}=0.016)$, respectively (Table III; Fig. 3). Proteinuria and hematuria were markedly decreased in six cases. Serum antinuclear antibody levels were negative in five patients and had decreased markedly in the additional eight patients. Anti-double-stranded DNA (anti-ds-DNA) antibody tests were positive in five patients at the baseline, but became negative at last follow-up examination in four patients. The anti-ds-DNA antibody titer decreased in the remaining patient. The SLE-DAI decreased significantly between $15 \pm 4$ and $6 \pm 2(\mathrm{P}<0.001)$. In total, 10 patients discontinued PD treatment due to the recovery of renal function, while three patients continued with a decreased dosage of PD for the improvement of renal function.

Complications. During the follow-up period, only one case developed peritonitis following diarrhea, and recovered via the administration of antibiotics. Two cases who received MMF treatment developed pneumonia, while one case developed peritoneal leakage.

\section{Discussion}

In total, 13 severe LN patients with AKI that had undergone PD therapy were reported in the study. PD was demonstrated to be a simple, safe, gentle and efficient renal replacement therapy method, with the ability to correct AKI-induced metabolic, electrolytic and acid-base disorder and volume overload. Compared with hemodialysis (HD), PD has been associated with faster recovery of renal function in AKI and better maintenance of residual function in patients with CKD $(9,10)$. This may be due to the improved cardiovascular tolerance associated with this renal replacement therapy method. This method presents episodes of hypotension (and consequently renal ischemia), and to be a lower level of activation of the inflammatory pathway, since the blood is not in contact with artificial membranes (11-13). PD is particularly suitable for patients with refractory heart failure or hemodynamically instable conditions where systemic anticoagulation should be avoided.

Data on PD treatment in severe LN cases are limited. Immunosuppressive therapy is the basic process to control lupus activity, however, this is limited in patients with complications such as RPGN or AKI. All the patients in the present study developed renal dysfunction to varying degrees, with Scr levels ranging between 4.24 and $9.48 \mathrm{mg} / \mathrm{dl}$. Conditions worsened due to oliguria and congestive heart failure, particularly following methylprednisolone pulse therapy. In this situation, PD therapy was selected for support. The results demonstrated that PD had marked effects for these patients. The majority of patients had time for the recovery of renal function and, more importantly, these patients reached a stable homeostasis following the administration of PD for one month, thus, it was possible to reapply immunosuppressants. PD is suitable therapy for patients with a high catabolism, oliguria, anuria, severe innutrition, water-sodium retention, prerenal failure and cardiovascular problems. All of the patients were followed up until the present study was completed.

It has been reported that patients behave differently within a short time period due to rapidly progressive LN. In $10-20 \%$ of these patients, renal function may recover or partly recover within a four-month period (14), allowing the cessation of HD. It has been reported that $10-28 \%$ of $\mathrm{LN}$ patients require renal replacement therapy to achieve partial remission from renal failure (15). In the present study, the 13 patients were found to have azotemia caused by active $\mathrm{LN}$, prerenal factors or steroids. There were a number of indicators, including enlargement of kidney size. Patients with active pathological changes, including crescents or loop necrosis, should be treated actively. Compared with HD, PD has little influence on the hemodynamics and preserves the RRF well $(16,17)$. PD has been shown to be more conducive to renal function recovery. In the 10 patients receiving immunosuppressive therapy assisted with PD, the RRF improved, the UV increased and Scr levels decreased gradually. In total, $76.9 \%$ (10/13) of the patients discontinued the PD treatment and had the PD catheters removed. For these patients, PD maintained the capability balance and removed nitrogen production. Thus, PD offered great support and safeguard for further treatment with immunosuppressants. In addition, nutrition improved since there was no limit in protein or other nutrient intake during 
PD. Therefore, we hypothesize that PD should be applied early for these $\mathrm{LN}$ patients. In order to preserve the RRF, body weight, UV and ultrafiltration should be monitored during PD. These parameters are not only used to decide the hypertonic dialysate in patients with heavy edema, but may also be used to estimate the RRF.

Immunosuppressants may be applied timely and reasonably during the PD process in order to further treat the primary disease. Previous studies have largely focused on the impact of immunological insults on SLE patients following dialysis (18). Nevertheless, the nonimmunological effects are also important. Therefore, renal survival may be more representative of predialysis lupus severity compared with the SLE-DAI or serological lupus activity. The use of immunosuppressive therapy in LN patients with severe renal insufficiency remains controversial. Due to long-term exposure to steroids or cytotoxic drugs, LN patients have been shown to have accelerated atherosclerosis and increased risks of infectious complications (19).

PD patients with LN have significantly lower predialysis levels of serum Alb and $\mathrm{Hb}$ compared with non-LN patients. In addition, $\mathrm{LN}$ patients are more likely to suffer from various infections due to hypoimmunity (19). Previous studies have revealed that when compared with non-LN patients undergoing CAPD, LN patients had a lower Alb level, more complications associated with infection and a poorer life quality (20-23). In the study by Andrews et al (24), risk factors for infectious complications included a significantly lower level of Alb at the start of PD as well as the patients being on immunosuppressives. In previous studies, a significantly higher incidence of peritonitis and other infections was observed in LN patients undergoing PD. The incidence of exit site infections was higher in the study by Liang et al (23). In addition, the overall mortality rate was higher in the SLE group (32\%) as compared with the control group (9\%). The effect of immunosuppression on the high incidence rate of peritonitis and other infections in PD patients is further documented by a study from Guy's Hospital (19). As well as short-term effects, peritonitis may have additional serious side effects. Peritonitis can induce exacerbations of the disease and may contribute to the development of encapsulating peritoneal sclerosis, particularly in lupus patients (25). Therefore, these results indicate that $\mathrm{PD}$ may not be the first choice for renal replacement therapy in lupus patients undergoing immunosuppressive therapy. However, we hypothesize that the purpose of PD adjuvant therapy in LN patients is not to treat the protopathy, but to protect the RRF and improve the azotemia and nutrition of the patients in order to earn time and improve the condition for further immunosuppressant treatment. Thus, all the patients in the present study continued to receive immunosuppressive therapy during PD and a number of them required immunosuppressants such as MMF. LN in these patients was shown to be controlled following treatment. Autoantibody levels in a number of patients turned negative, complement levels were elevated to a normal level, urinalysis was improved, RRF was recovered and dialysis treatment was ceased.

The incidence of infectious complications was high. In order to prevent these complications, prednisone treatment was decreased to $10 \mathrm{mg} /$ day prior to surgery. Interventions to reduce catheter-associated infections included sterile placement techniques, appropriate local dressing and catheter care.
Full-time doctors and nurses performed these procedures. Follow-up via telephone was regularly conducted by nurses. In the group of 13 patients, only one individual developed peritonitis and two patients developed pneumonia. In addition, the incision was difficult to heal and leakage of the dialysate occurred easily. Thus, two pockets were ligated during surgery and a small dosage of dialysate was applied following surgery; the initial dose was $1,000 \mathrm{ml}$ per time and this was performed three to four times daily, gradually increasing the dose. All the patients healed without infection, with the exception of one case that had dialysate leakage. Following pausing PD and undergoing hemofiltration, the leakage was stopped and PD was continued.

The cost of PD is lower than hemofiltration. In the present study, the expenses of PD were $\$ 120$ per week at a dose of $6,000 \mathrm{ml}$ per day, while the expenses of hemofiltration were at least $\$ 714$ per week. PD patients were able to manage by themselves conveniently without any interruption of daily life. The time of renal function recovery was difficult to estimate. A total of 10 patients in the group recovered in 1-4 months following PD. One case achieved gradual remission with PD over 15 months. Long-term hemofiltration is likely to result in a heavy economic burden.

PD not only improves the fluid and electrolyte imbalance, but also significantly reduces the effect of systemic cytokines. PD can clear cytokines, including interleukin (IL)-6, IL-10 and tumor necrosis factor- $\alpha$ (26). Future research should focus on the associations among inflammatory factors, severity and duration in the acute phase of SLE.

In conclusion, PD is not only a replacement method, but also a therapy. PD is an adjuvant method that may be used for treating LN patients complicated with severe organ dysfunction. PD can preserve the RRF, improve the nutritional status of the patients and provide conditions and guarantees for further immunosuppressive therapy of SLE. In contrast to others studies, the results of the present study, with low infection and mortality rates coupled with a high rate of recovery of renal function, indicate that PD can be considered as a treatment option for patients with severe $\mathrm{LN}$ and $\mathrm{AKI}$ who require ongoing immunosuppressive therapy.

\section{References}

1. Zhu X, Li F, Yang B, Liang J, Qin H and Xu J: Effects of ultraviolet $\mathrm{B}$ exposure on NDA methylation in patients with systemic lupus erythematosus. Exp Ther Med 5: 1219-1225, 2013.

2. Fayaz A, Pirson Y, Cosyns JP, Yango L and Lambert M: Pauci-immune necrotizing and crescentic glomerulonephritis in a patient with systemic lupus erythematosus. Clin Nephrol 69: 290-293, 2008

3. Rao L, Liu G, Li C, Li Y, Wang Z, Zhou Z, Tong S and Wu X: Specificity of anti-SSB as a diagnostic marker for the classification of systemic lupus erythematosus. Exp Ther Med 5: 1710-1714, 2013.

4. Soni S and Saboo S: High-volume peritoneal dialysis in acute kidney injury. Kidney Int 75: 1119, 2009.

5. Ren W, Chen W, Pan HX, Lan L, Wang P, Huang YH, Kong M and Wang K: Clinical application of right low-position modified peritoneal dialysis catheterization. Exp Ther Med 5: 457-460, 2013.

6. Rietveld A and Berden JH: Renal replacement therapy in lupus nephritis. Nephrol Dial Transpl 23: 3056-3060, 2008.

7. Zhang ZY, Zhou CH, Li MX and Yu YW: Long-term efficacy of intermittent peritoneal dialysis using various doses. Exp Ther Med 3: 519-524, 2012 
8. Shaw LM, Nicholls A, Hale M, Armstrong VW, Oellerich M, Yatscoff R, Morris RE, Holt DW, Venkataramanan R, Haley J, Halloran P, Ettenger R, Keown P and Morris RG: Therapeutic monitoring of mycophenolic acid. A consensus panel report. Clin Biochem 31: 317-322, 1998.

9. Wang A, Wang Y, Wang G, Zhou Z and Yang X: Infective endocarditis associated with acute renal railure: Repeat renal biopsy and successful recovery. Exp Ther Med 1: 433-436, 2010.

10. Chionh CY, Ronco C, Finkelstein FO, Soni SS and Cruz DN: Acute peritoneal dialysis: what is the 'adequate' dose for acute kidney injury? Nephrol Dial Transplant 25: 3155-3160, 2010.

11. Stenvinkel P, Chung SH, Heimbürger $\mathrm{O}$ and Lindholm B Malnutrition, inflammation, and atherosclerosis in peritoneal dialysis patients. Perit Dial Int 21 (Suppl 3): S157-S162, 2001

12. Li L, Wang R, Shi HH, Xie L, Li JD, Kong WC, Tang JT, Ke DN and Zhao LY: In vitro study on the feasibility of magnetic stent hyperthermia for the treatment of cardiovascular restenosis. Exp Ther Med 6: 347-354, 2013.

13. Takahashi T, Kubota M, Nakamura T, Ebihara I and Koide $\mathrm{H}$ Interleukin-6 gene expression in peripheral blood mononuclear cells from patients undergoing hemodialysis or continuous ambulatory peritoneal dialysis. Ren Fail 22: 345-354, 2000.

14. Coplon NS, Diskin CJ, Petersen J and Swenson RS: The long-term clinical course of systemic lupus erythematosus in end-stage renal disease. N Engl J Med 308: 186-190, 1983.

15. Cheigh JS and Stenzel KH: End-stage renal disease in systemic lupus erythematosus. Am J Kidney Dis 21: 2-8, 1993.

16. Zhou F, Ji J, Song Q, Peng Z, Zhang G and Wang Y: Pulmonary fat embolism and related effects during femoral intramedullary surgery: An experimental study in dogs. Exp Ther Med 6: 469-474, 2013.

17. Gabriel DP, Caramori JT, Martin LC, Barretti P and Balbi AL: Continuous peritoneal dialysis compared with daily hemodialysis in patients with acute kidney injury. Perit Dial Int 29 (Suppl 2): S62-S71, 2009
18. Rodby RA, Korbet SM and Lewis EJ: Persistence of clinical and serologic activity in patients with systemic lupus erythematosus undergoing peritoneal dialysis. Am J Med 83: 613-618, 1987.

19. Altieri P, Sau G, Cao R, Barracca A, Menneas A, Micchittu B, Cabiddu G, Esposito P and Pani A: Immunosuppressive treatment in dialysis patients. Nephrol Dial Transplant 17 (Suppl 8): 2-9, 2002.

20. Siu YP, Leung KT, Tong MK, Kwan TH and Mok CC: Clinical outcomes of systemic lupus erythematosus patients undergoing continuous ambulatory peritoneal dialysis. Nephrol Dial Transplant 20: 2797-2802, 2005.

21. Tachaudomdach C, Kantachuvesiri S, Changsirikulchai S, Wimolluck S, Pinpradap K and Kitiyakara C: Connective tissue growth factor gene expression and decline in renal function in lupus nephritis. Exp Ther Med 3: 713-718, 2012.

22. Weng CH, Hsu CW, Yu CC, Yen TH, Yang CW and Hung CC: Peritoneal dialysis and hemodialysis in systemic lupus erythematosus patients: comparison of clinical outcomes. Kidney Blood Press Res 32: 451-456, 2009.

23. Liang CC, Huang CC, Wang IK, Chang CT, Chen $\mathrm{KH}$, Weng $\mathrm{CH}$, Lin JL, Hung CC, Yang CW and Yen TH: Impact of renal survival on the course and outcome of systemic lupus erythematosus patients treated with chronic peritoneal dialysis. Ther Apher Dial 14: 35-42, 2010.

24. Andrews PA, Warr KJ, Hicks JA and Cameron JS: Impaired outcome of continuous ambulatory peritoneal dialysis in immunosuppressed patients. Nephrol Dial Transplant 11: 1104-1108, 1996.

25. Odama UO, Shih DJ and Korbet SM: Sclerosing peritonitis and systemic lupus erythematosus: a report of two cases. Perit Dial Int 19: 160-164, 1999.

26. Szakszon K, Csízy I and Szabó T: Early introduction of peritoneal dialysis may improve survival in severe sepsis. Pediatr Emerg Care 25: 599-602, 2009. 